\title{
O sistema fonológico das vogais orais na língua indígena Aikanã
}

\author{
Patrícia Goulart Tondineli ${ }^{1}$ \\ Fundação Universidade Federal de Rondônia - UNIR, Porto Velho, Rondônia, Brasil
}

Resumo: Esta pesquisa insere-se no projeto Línguas indígenas do Cone-Sul de Rondônia e objetiva apresentar análise comparativa de estudos já realizados sobre o sistema fonéticofonológico vocálico da língua Aikanã, com o fim de constituirmos o quadro fonológico de vogais orais da língua em estudo. A partir de pesquisa bibliográfica de estudos realizados por Vasconcelos (2002), Ribeiro e Cândido (2006), Silva (2012), Voort (2013) e Birchall (apud STORTO, 2019), traçamos um quadro comparativo das postulações fonéticas e as fonológicas. Verificamos a falta de consenso entre os linguistas quanto ao sistema vocálico fonético-fonológico da língua Aikanã, motivo pelo qual introduzimos, nessa comparação, transcrições feitas por nós a partir do mito indígena Tracajá. Para dirimir quaisquer dúvidas quanto ao sistema de vogais orais em seu nível fonológico, recolhemos palavras da língua com o fim de identificarmos pares mínimos, para que efetivamente se distinguissem os processos de alofonia dos fonemas propriamente ditos. O que pudemos comprovar inicialmente é que a língua Aikanã possui um quadro fonológico de nove vogais orais, o qual contempla dez universais apontados por Crothers (apud BOER, 2001).

Palavras-chave: Línguas Indígenas; Aikanã; Sistema Fonológico; Vogais Orais.

Title: The phonological system of oral vowels in the indigenous language Aikanã

Abstract: This research inserts in the project Línguas indígenas do Cone-Sul de Rondônia and aims to present comparative analysis of studies already conducted on the phonetic-phonological system of the Aikanã language, in order to constitute the phonological system of oral vowels of the language under study. From bibliographical research of studies conducted by Vasconcelos (2002), Ribeiro and Cândido (2006), Silva (2012), Voort (2013) and Birchall (apud STORTO, 2019), we charted a comparative framework covering phonetic and phonological postulates. What we could initially verify is the lack of consensus among the linguists about the phonetic-phonological vowel system of the Aikanã language, which is why we introduced, in this comparison, transcriptions made by us from the indigenous myth Tracajá. To resolve any doubts about the system of oral vowels at its phonological level, we collect words from the language in order to identify minimum pairs, so that the processes of phoneme alophony were effectively distinguished themselves. What we could prove initially is that the Aikanã language has a phonological picture of 9 oral vowels, which includes 10 universals appointed by Crothers (apud BOER, 2001).

Keywords: Indigenous Languages; Aikanã; Phonological System; Oral Vowels.

\footnotetext{
${ }^{1}$ Doutora em Linguística pela Pontifícia Universidade Católica de Minas Gerais (PUCMG). Professora Adjunta do curso de Letras da Fundação Universidade Federal de Rondônia (UNIR). Coordenadora do Grupo de Pesquisa em Estudos da Língua(gem) - GPEL - e do projeto de pesquisa Línguas Indígenas do Cone-Sul de Rondônia. Orcid: https://orcid.org/0000-0002-8326-8242. E-mail: patrícia.tondineli@unir.br
} 


\section{Introdução}

Este estudo, que faz parte do projeto de pesquisa Línguas indígenas do Cone-Sul de Rondônia, do GPEL, Grupo de Pesquisa em Estudos da Língua(gem), tem como objetivo maior a compreensão mais integrada dos fatos da língua Aikanã. Assim sendo, e tendo em vista o inegável crescimento da pesquisa com línguas indígenas no país, faz-se mister efetuar uma revisão de trabalhos já efetuados, tanto para que se possa visualizar melhor a língua em estudo quanto para que possa servir de norte para estudos posteriores e atualizados.

Tal análise comparativa permite verificar variações e mudanças nos sistemas linguísticos, no nosso caso, no sistema fonético-fonológico, mais especificamente, no sistema vocálico da língua Aikanã. Como expõe Wetzels (1995):

[...] a relação entre dados de línguas indígenas e a teoria fonológica é uma relação de interesse mútuo. Embora a teoria linguística tenha sido construída sem ser capaz de contar com uma quantidade representativa de descrições das línguas indígenas, ela é, em essência, uma teoria universal. Podemos, portanto, esperar que a aplicação de uma teoria moderna à análise de línguas indígenas aumentará nossa compreensão do modo como línguas indígenas são estruturadas. Por outro lado, o fato de que línguas indígenas da América do Sul tenha seguido sua própria evolução isolada por pelo menos dez milênios (talvez muito mais) torna provável que elas tenham desenvolvido traços linguísticos que são únicos de um ponto de vista tipológico. (WETZELS, 1995, p. 3).

Apresentamos, assim, uma descrição dos segmentos vocálicos do Aikanã, considerando as propriedades articulatórias do aparelho fonador. Para tanto, tomamos, para a análise, o levantamento feito por Vasconcelos (2002), Ribeiro e Cândido (2006), Silva (2012), Voort (2013) e Birchall (apud STORTO, 2019), além de transcrição realizada do texto O Tracajá (2006), material coletado e gravado pela equipe de pesquisadores do Museu Paraense Emílio Goeldi.

Ressaltamos que não intentamos fornecer uma análise exaustiva dos processos fonético-fonológicos da língua Aikanã; consequentemente, restringimos a nossa descrição fonético-fonológica a parâmetros articulatórios, optando por não discutir sobre os aspectos suprassegmentais e prosódicos.

\section{A língua Aikanã}

Os Aikanã são também listados na literatura como “Massaká, Kassupá, Huarí, Corumbiara, Mondé, Tubarão", entre outros nomes. Destes, pelo fato de descenderem "de certos subgrupos históricos", além de Aikanã, "também se autodenominam Kasupa, Masaka ou Munde" (VOORT, 2013, p. 360).

No levantamento feito por Hein van der Voort, é em 1948 que Cândido Mariano da Silva Rondon e João Barbosa de Faria, em "um mapa desenhado com base em informações dadas por um cacique Kepkiriwat em 1913", citam pela primeira vez os Aikanã, "sob o nome 
Uapuruta, que representa o subgrupo antigo dos Waykuruta", ou Waikorotá, ou Waypurutá?e $e^{2}$ como também se "chamavam os Aikanã" (VOORT, 2013, p. 360).

Em 1915, o "etnógrafo sueco barão Erland Nordenskiöld [...] descreve seu encontro com o povo Huarí nas cabeceiras do rio Corumbiara", etnônimo dado aos Aikanã "pelo (hoje extinto) povo Pauserna", cuja lista de palavras publicada por Nordenskiöld permanece praticamente idêntica à que se verifica hoje na língua Aikanã (VOORT, 2013, p. 360).

Atualmente, a língua Aikanã, conforme expõe o Atlas Interativo de Línguas em Perigo (UNESCO, 2010), está definitivamente ameaçada de extinção. Falada por aproximadamente 200 pessoas (incluindo as crianças abaixo de 5 anos), cuja maioria de seus falantes vive na Terra Indígena Tubarão Latundể ${ }^{3}$ é considerada língua isolada:

[...] the usual characterization in the literature of Aikanã, Kanoê and Kwaza as isolated languages is worth just as much as the various proposals for their specific classification: since there were only a few word lists, all claims were based on very thin evidence. Van der Voort (2005b) made an attempt at the classification of the 'isolated' languages of Rondonia on the basis of new and comprehensive data collections and descriptive analyses of a number of languages. The evidence presented in the article suggests that genetic relationships among these three languages could be possible, be it that they must be more ancient than those that define the Tupian family for example.

The impression one gathers for the Guaporé-Mamoré region is that speakers of the languages under discussion have been in contact with one another for many centuries, leading to the emergence of a Sprachbund. (CREVELS; VOORT, 2008, p. $169)^{4}$.

Como se verifica, não há provas conclusivas para relações genealógicas entre essas três línguas; assim, parece provável que sejam verdadeiramente isoladas, mas que sofreram a influência umas das outras durante muitos séculos, como comprova a hipótese de Sprachbund ${ }^{5}$ (CREVELS; VOORT, 2008).

Especificamente quanto à sua estrutura, a língua Aikanã apresenta alta complexidade morfológica, tendo nos verbos a maior prova de tal fato, com sufixos que, além de marcarem tempo, modo e aspecto, podem mudar sua valência verbal (BIRCHALL et al., 2017, p. 406).

Com sentenças preferencialmente na ordem SOV, os substantivos, os verbos e os advérbios constituem as três classes principais de palavras, cujas sílabas possuem como “estrutura básica [...] (C)(G)V(G)." (VOORT, 2013, p. 362).

\footnotetext{
2 "com o sufixo -Pe, que indica o plural em Salamãi." (CASPAR, 1975, apud VOORT, 2013, p. 360).

${ }^{3}$ Situada no município de Chupinguaia, no Cone-Sul de Rondônia, cuja população é de 227 pessoas (FUNAI, 2017) distribuídas em três aldeias: Tubarão, Rio do Ouro e Latundê.

4 “[...] a caracterização usual na literatura do Aikanã, Kanoê e Kwaza como línguas isoladas vale tanto quanto as várias propostas para sua classificação específica: como havia apenas algumas listas de palavras, todas as reivindicações foram baseadas em evidências muito escassas. Van der Voort (2005b) tentou a classificação das línguas 'isoladas' de Rondônia com base em novas e abrangentes coletas de dados e análises descritivas de uma série de idiomas. As evidências apresentadas no artigo sugerem que as relações genéticas entre essas três línguas poderiam ser possíveis, sejam elas mais antigas do que aquelas que definem a família Tupi, por exemplo. A impressão que se reúne para a região de Guaporé-Mamoré é que os falantes das línguas em discussão têm estado em contato uns com os outros há muitos séculos, levando ao surgimento de um Sprachbund." (CREVELS; VOORT, 2008, p. 169, tradução nossa).

${ }^{5}$ Área linguística ou área de convergência linguística.
} 
No nível fonológico da língua Aikanã, verifica-se "inventário fonêmico [...] de 5-6 vogais orais, de 5 vogais nasais e de 10-13 consoantes." (SILVA, 2012, p. 14, grifos nossos). Já para Vasconcelos (2002) e para Voort (2013):

\begin{abstract}
O sistema fonológico segmental do Aikanã apresenta dezesseis (16) consoantes, seis (06) vogais orais e quatro (04) nasais. Não estão incluídos neste inventário alguns sons que são claramente empréstimos da língua nacional, como a oclusiva velar sonora [g] e as fricativas [f, $v, z, Z$ ], os quais são observados na fala cuidadosa, em nomes de pessoas e de localidades ou regiões que, necessariamente figuram na fala dos Aikanã. No entanto, como é de se esperar, no discurso normal ou rápido, os falantes quase sempre fazem a substituição de cada um dos referidos sons pelo som correspondente mais próximo em sua própria língua. Portanto, quando figurarem nos dados, tais sons estarão sendo considerados meramente como empréstimos. (VASCONCELOS, 2002, p. 09, grifos nossos).

Com base em pares mínimos encontrados, pode-se supor que o sistema fonológico da língua abrange pelo menos dez vogais: /a, e, i, o, u, ü, ã, ẽ, ĩ, ũ/. [...] /a/ [a], mas

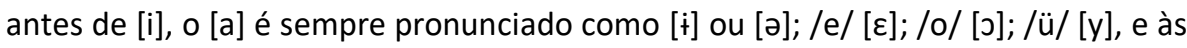

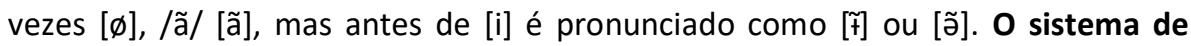
consoantes contém 16 fonemas: /p, b, t, d, k, ?, h, ts, tx, m, n, ñ, r, w, z, y/. No início da palavra, o/ts/ é frequentemente pronunciado como [s], mas entre vogais é frequentemente [ts], com alguma variação livre com $[\mathrm{s}]$. $0 / \mathrm{tx} /$ é geralmente $[\mathrm{t}]$ ], mas []] foi observado também. $O / \tilde{n} /$ é [n] ou [j]. O /z/ é normalmente pronunciado como a fricativa [ठ], e às vezes como laminal [z], e pode ser nasalizado entre vogais nasais, assemelhando-se $a[n] .0 / k /$ às vezes recebe palatalização $\left[k^{j}\right]$ antes de $[e] .0 / y /$ é pronunciado normalmente como [j], mas antes do [i] e [ø] é pronunciado como [3]. (VOORT, 2013, p. 362, grifos nossos).
\end{abstract}

Tanto Voort (2013) quanto Vasconcelos (2002) apresentam visão similar quanto ao inventário fonológico da língua Aikanã, composto por um quadro de 10 vogais e de 16 consoantes. Especificamente no que tange ao quadro vocálico, no nível fonológico, há discrepância quanto à altura de /e/, que figura ora como média, conforme Voort (2013), ora como média baixa, como aponta Vasconcelos (2002, p. 22), para quem o estatuto fonológico da língua Aikanã possui seis vogais orais, "(/i/, / //, /ö/, /a/ /u//o/)", quadro que se repete quanto à nasalização de /e/.

Divergências como a altura da vogal /e/ também são listados nos inventários fonéticofonológicos de outros estudos, o que torna, portanto, essencial uma análise comparativa dos dados, o que desenvolvemos a seguir quanto às vogais orais.

\title{
Sistemas vocálicos
}

Os sistemas vocálicos das línguas do mundo podem variar em quantidade e qualidade de vogais. Boer (2001, p. 7) encontra, em seus estudos de 421 inventários fonêmicos de distintos sistemas linguísticos, 921 segmentos diferentes: 652 consoantes, 89 ditongos e 180 vogais. Sobre estas últimas, as mais comuns na composição do inventário vocálico são "[i], [e], [a], [o], e [u]", sistema mais frequente entre as 317 línguas que compõem a versão do UCLA 
Phonological Segment Inventory Database - UPSID - analisada por Vallée ${ }^{6}$ (apud BOER, 2001, p. 9, tradução nossa). Baseando-se em estudos de Crothers (1978), Boer (2001) apresenta um diagrama de sequências de vogais usadas em diferentes inventários vocálicos das línguas do mundo:

Figura 1 - Hierarquia do sistema vocálico (CROTHERS, 1978)

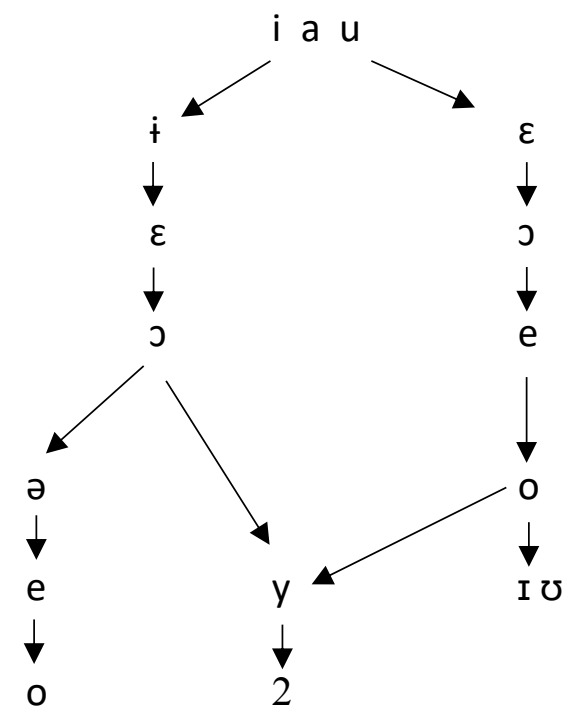

Fonte: Boer (2001, p. 89).

A partir da hierarquização vocálica, Crothers (1978) sumariza suas observações em uma série de regras, a saber:

1. All languages have /i a u/.

2. All languages with four or more vowels have $/ \mathfrak{t} /$ or $/ \varepsilon /$.

3. Languages with five or more vowels have $/ \varepsilon /$. They genarally also have $/ \supset /$.

4. Languages with six or more vowels have $/ \mathrm{J} /$ and also either $/ \mathrm{i} /$ or $/ \mathrm{e} /$, generally the former.

5. Languages with seven or more vowels have /e o/ or / $₫$ ə/. (The types / + ə/ may be represented by /ü ö/.)

6. Languages with eight or more vowels have /e/.

7. Languages with nine or more vowels generally have /o/.

8. A contrast between five basic vowel qualities is the norm for human language, and in general, the most common systems are those with close to this number of basic vowels.

9. The number of height distinctions in a system is typically equal too $r$ greater than the number of backness distinctions.

10. Language with two or more interior vowels always have a high one.

11. The number of vowels in a column of interior vowels cannot exceed the number in the front or back columns.

12. The number of height distinctions in front vowels is equal too $t$ greater than the number in back vowels ${ }^{7}$. (BOER, 2001, p. 89-90).

\footnotetext{
6 "The most common vowel system is the one consisting of [i], [e], [a], [o], and [u]. This occurs in 34 of the 317 languages (VALLÉE 1994) [...]" (BOER, 2001, p. 9).

7 "1. Todas as línguas possuem /i a u/. 2. Todas as línguas com quatro ou mais vogais possuem /itou / $\varepsilon /$. 3. As línguas com cinco ou mais vogais possuem $/ \varepsilon /$. Geralmente também possuem / /. 4. As línguas com seis ou mais vogais possuem / / / e também / + / ou /e/, geralmente a primeira. 5 . As línguas com sete ou mais vogais possuem /e o/ ou /† ə/. (Os tipos /† ə/ podem ser representados por /ü ö/.) 6. As línguas com oito ou mais vogais possuem
} 
Já para Silva (2008, p. 33), em consonância com o que expõe Maddieson (1984), "a partir dos dados do Phonological Segment Inventory Database (UPSID) - banco de dados com informações sobre os inventários de 317 línguas", o inventário mínimo é de três vogais, "sendo que apenas 5,7\% das línguas" possuem esse sistema, "como Mura, Gugu-Yalanji e Alabama". Já o inventário máximo é de 24 vogais, presente em "aproximadamente $4,1 \%$ das línguas [...] entre as quais estão o Hunzib e o Khmer" (SILVA, 2008, p. 33). Expõe ainda a autora:

O sistema composto por cinco vogais é mais frequente nas línguas, estando presente em $21,5 \%$ destas. Quanto à qualidade, o sistema mais frequente é aquele composto por cinco qualidades de vogais, ocorrendo em 30,9\% das línguas. Conforme dados do UPSID, em uma língua com cinco vogais geralmente estão presentes /a, $\varepsilon, i, ~ o, u /$, o que ocorre em um quarto das línguas descritas no banco de dados. Maddieson (1984, p.128) destaca que duas em três línguas do mundo têm de 5 a 7 qualidades vocálicas, seguido daquelas que distinguem 10 qualidades de vogais. (SILVA, 2008, p. 33-4).

Ainda de acordo com o UPSID, quanto às línguas brasileiras, é possível identificar "14 línguas indígenas: o Irantxe, o Nambikwara do Sul, o Wapishana, o Apinajé, o Kawaio, o Hixkaryana, o Kaingang, o Guarani Mbyá, o Maxakali, o Trumaí, o Bakairi, o Barasana, o Boror e o Tikuna." (RIBEIRO; CÂNDIDO, 2006, p. 3). Dizem ainda os autores que, de acordo com a base de dados do UPSID, a média de fonemas usados nas línguas do mundo é de "20 e 37 fonemas (cf. MADDIESON, 1984)". Já quanto ao inventário fonêmico, o mínimo é de 11 fonemas, "como ocorre no Rotokas, [...], falado na Papua-Nova Guiné, (FIRCHOW; FIRCHOW, 1969) e no Pirahã, pertencente à família Mura, falado no Brasil e na Colômbia (EVERETT, 1982)", e o máximo é de 141 fonemas, "conforme registrado no !Xũ, língua da família Khoisaon, falada na Namíbia (SNYMAN, 1970)", como expõem Ribeiro e Cândido (2006, p. 4). Já quanto à quantidade de fonemas vocálicos, verifica-se, minimamente, dois fonemas vocálicos orais "no Kabardian, uma língua Norte-Caucasiana que apresenta [...] a alta posterior [u] e a baixa central [a]" (RIBEIRO; CÂNDIDO, 2006, p. 4). Para os autores,

isso significa que as línguas naturais do mundo geralmente usam só um pequeno subconjunto dos fones disponíveis. Esse subconjunto também não é aleatório. Alguns fones ocorrem mais freqüentemente do que outros. Por exemplo, a vogal baixa [a] ocorre em $87 \%$ das línguas da UPSID, enquanto a média-baixa arredondada [œ] ocorre somente em $2 \%$ delas, isto é, muito raramente. Outra informação importante dada pela base UPSID diz respeito à simetria dos inventários de fonemas, os quais, de acordo com os dados disponíveis, tendem a ser simétricos. Isto é, se um repertório de fones vocálicos contiver, por exemplo, a média baixa / $/$ nas línguas do UPSID, há grandes possibilidades de que ele seja acompanhado por sua

/e/. 7. As línguas com nove ou mais vogais geralmente possuem /o/. 8. Um contraste entre cinco qualidades básicas de vogais é a norma para a linguagem humana, e, em geral, os sistemas mais comuns são aqueles com um número próximo deste número de vogais básicas. 9. O número de distinções de altura num sistema é normalmente maior do que o número de distinções de anterioridade. 10. A língua com duas ou mais vogais interiores possuem sempre uma alta. 11. O número de vogais internas não pode exceder o número de vogais anteriores ou posteriores. 12. O número de distinções de altura nas vogais anteriores é maior do que nas vogais posteriores." (BOER, 2001, p. 89-90, tradução nossa). 
contraparte anterior, ou seja, $/ \varepsilon /$. Os dados revelam que / / é quase cinco vezes mais freqüente nos sistemas lingüísticos quando for acompanhado de $/ \varepsilon /$. De fato, das línguas em que /J/ ocorre, em somente $18 \%$ o segmento / $\varepsilon /$ não foi registrado. (RIBEIRO; CÂNDIDO, 2006, p. 4).

Em relação às línguas indígenas brasileiras, Ribeiro e Cândido (2006), analisando dados relativos às vogais orais de 107 línguas, concluem ser bastante semelhante o quadro vocálico das línguas indígenas e das demais línguas do mundo. Ressaltam, entretanto, alguns detalhes, a saber:

a) "discrepância entre a porcentagem de línguas em que ocorre a vogal alta central não arredondada / $\mathfrak{t} /$ no Brasil $(74,8 \%)$ e no restante do mundo $(13,5 \%)$ ", o que pode levar à hipótese de que "a presença de /ł/ pode ser uma propriedade tipológica das línguas brasileiras", aventando, consequentemente, "a hipótese de que essa é uma característica do tronco Ameríndio proposto por Greenberg (1987)" (RIBEIRO; CÂNDIDO, 2006, p. 10).

b) "[...] 80,4\% das línguas brasileiras possuem esse sistema tripartido de vogais": /a/, /i/ e /u/, "conseqüência natural da chamada Teoria da Dispersão", em que "as vogais são eficientemente distribuídas no espaço acústico vocálico, de tal maneira a maximizar a distinção perceptual, permitindo um certo grau de imprecisão na produção" (RIBEIRO; CÂNDIDO, 2006, p. 10).

c) "[...] a ocorrência das vogais altas /i/ e /u/ é tão comum quanto a da vogal baixa /a/", sendo este "o primeiro universal lingüístico citado por Crothers (1978)" (RIBEIRO; CÂNDIDO, 2006, p. 11).

d) "[...] nas línguas indígenas brasileiras, 97,4\% das vogais orais são anteriores nãoarredondadas, enquanto $93,0 \%$ são não baixas posteriores arredondadas", característica que também pode ser associada aos universais linguísticos, bem como o fato de "98\% das vogais baixas são [serem] não-arredondadas" (RIBEIRO; CÂNDIDO, 2006, p. 11).

e) Ainda tratando de universais, evidenciam: "se uma língua possui as vogais anteriores arredondadas, como por exemplo /y/ e / $\varnothing /$, logo, nela há também as vogais posteriores arredondadas /u/ e /o/", o que pôde ser "rigorosamente atestado pelos dados da língua dos Pacaasnovas, a única da base que apresenta essa combinação rara de fonemas vocálicos" (RIBEIRO; CÂNDIDO, 2006, p. 11).

f) "[...] alguns fonemas vocálicos [...] são totalmente ausentes nas línguas brasileiras, o que pode também ser um indício de ligação genética"; por outro lado, /ə/ encontrase, nas línguas brasileiras, em igual percentual das demais línguas faladas no mundo (RIBEIRO; CÂNDIDO, 2006, p. 11).

g) "[...] preferência pelas vogais mais altas /e/ e /o/ em detrimento do conjunto das mais baixas $/ \varepsilon /$ e $/ \supset / /$ ", o que, de acordo com os dados do UPSID, "é o contrário do que costuma ocorrer na maioria das línguas do mundo" (RIBEIRO; CÂNDIDO, 2006, p. 11). 
h) "[...] o sistema fonológico de vogais orais mais comum nas línguas indígenas brasileiras é aquele que comporta 6 segmentos": /i, $\dot{i}, \mathrm{u}, \mathrm{e}, \mathrm{o}, \mathrm{a} /$ (RIBEIRO; CÂNDIDO, 2006, p. 12).

i) "Em termos gerais, 73 das 107 línguas indígenas [...] apresentam um sistema de sons vocálicos simétrico, ou seja, $68,22 \%$. Em contrapartida, 34 línguas contam com um sistema assimétrico, ou seja, 31,8\%." (RIBEIRO; CÂNDIDO, 2006, p. 13).

Segundo Storto (2019), os exemplos mais populares da fonética vocálica, identificando traços de anterioridade, posterioridade e altura são: /i, i, u, e, ə, 3, o, a/. Ainda:

\begin{abstract}
As línguas brasileiras relatadas em Storto e Demolin (2012) têm entre 3 e 10 qualidades vocálicas fonêmicas, ou seja, diferenças que são responsáveis por distinções lexicais. Se levarmos em conta nasalidade (vogais nasais), duração (vogais longas) e laringalização (vogais laringalizadas, produzidas com fonação rangeada ou rangida), os sistemas vocálicos podem dobrar, triplicar ou quadruplicar. Uma característica encontrada nos sistemas vocálicos das línguas brasileiras é que vogais anteriores são mais comuns que vogais posteriores. A vogal alta posterior / $u$ / é um alofone de /o/ em algumas subfamílias de línguas Tupi. Uma língua Yanomami (Yanam) perdeu o /u/ e há sistemas fonológicos formados por três, quatro e cinco vogais sem o/u/. Além disso, a vogal central alta /ł/ está quase sempre presente nos sistemas fonológicos das línguas brasileiras. (STORTO, 2019, p. 134).
\end{abstract}

Expostos os dados gerais do sistema vocálico das línguas indígenas brasileiras, retomamos ao nosso objetivo específico: descrever e comparar o sistema fonético-fonológico das vogais orais do Aikanã. Para tal, inicialmente, consideraremos os estudos já realizados sobre a fonologia da língua, mais especificamente Vasconcelos (2002), Ribeiro e Cândido (2006), Silva (2012), Voort (2013) e Birchall (apud STORTO, 2019), e o que esses autores propõem para o inventário de vogais orais do Aikanã. Em seguida, apresentaremos uma análise comparativa das vogais, cujos dados serão acrescidos daqueles obtidos por meio da transcrição do texto O Tracajá (2006), como descrito anteriormente.

\title{
Sistema vocálico do Aikanã
}

Com o fim de constituirmos o quadro fonológico de vogais orais da língua em estudo, efetuamos, inicialmente, uma revisão bibliográfica de estudos já realizados, a saber: Vasconcelos (2002), Ribeiro e Cândido (2006), Silva (2012), Voort (2013) e Birchall (apud Storto, 2019). Como as pesquisas foram feitas em momentos diferentes, tal fato pode, inclusive, nos permitir verificar variações diacrônicas.

Os dados serão apresentados, portanto, cronologicamente; entretanto, antes de adentrarmos especificamente no sistema vocálico do Aikanã, necessário se faz descrever sucintamente a metodologia de cada um deles. 
Resumo metodológico dos trabalhos analisados de deste estudo

O primeiro trabalho que compõe a nossa amostragem é o de Vasconcelos (2002). Seus dados foram coletados in loco, na Terra Indígena Tubarão Latundê, em quatro momentos diferentes: nos anos de 1988, 1991, 1992 e 1994. A autora afirma que a duração desses momentos foi de "aproximadamente três meses" (VASCONCELOS, 2002, p. 06).

A pesquisa de campo de Vasconcelos (2002) resultou em dados "oriundos principalmente de três falantes: Luciana Aikanã, Luzia Aikanã e Luiz Aikanã, pai das duas primeiras", registrando-se "tanto histórias, quanto palavras isoladas e sentenças envolvendo atividades, eventos e situações do quotidiano da vida na aldeia." (VASCONCELOS, 2002, p. 08).

Intentando servir de ponto de partida para novos e diversos estudos da língua Aikanã, objetivou apresentar descrição do quadro fonológico dessa língua indígena, assim como de questões relativas à morfologia verbal. Utilizou-se, para tal, "suporte teórico-metodológico [...] tanto do estruturalismo quanto do funcionalismo", tomando "como base as funções que determinadas estruturas lingüísticas desempenham no uso de uma certa língua, qualquer que seja o nível focalizado durante a análise." (VASCONCELOS, 2002, p. 08).

O segundo trabalho a que nos valemos nesta análise comparativa é o de Ribeiro e Cândido (2006), que objetivaram descrever o inventário fonológico de vogais orais de 107 línguas indígenas brasileiras. Para construir a base de seu trabalho, utilizam dados do Ethnologue: languages of the world (GORDON; RAYMOND, 2005), obtidos "com apoio de trabalhos descritivos de fonética e fonologia dessas línguas que estão disponíveis na literatura" (RIBEIRO; CÂNDIDO, 2006, p. 5).

As autoras, para compor a base de dados de sua pesquisa, tomam como critério "línguas da maioria das famílias classificadas do Brasil", o que resultou em corpus composto de "23 línguas da família Tupi; 19, Macro-Jê; 9, Karib; 10, Tukano; 10, Pano; 3, Nambikwara; 1, Txapakura; 1, Mura; 1, Guaykuru; 2, Jabuti; 10, Aruák; 7, Arawá; 4, Maku; 1, Yanomamie e 6 línguas de famílias isoladas." (RIBEIRO; CÂNDIDO, 2006, p. 5).

Já Silva (2012), em seu levantamento lexical Aikanã-português, compõe um dicionário composto de "1.305 verbetes e 1.640 exemplos", objetivando "fornecer um conjunto de dados para os linguistas e as escolas indígenas, e estimular mais pesquisas sobre a estrutura gramatical desta língua." (SILVA, 2012, p. 7). Utilizando questionários, dicionário bilíngue e obras sobre a fauna e a flora brasileira como suporte teórico, coletou os dados durante "nove meses vividos entre os aikanã da Terra Indígena Tubarão Latundê nas aldeias Gleba e Rio do Ouro." A autora afirma que as informações vieram de toda a comunidade indígena; entretanto, a pesquisa teve como principais informantes "a senhora Raimunda Aikanã e [...] seu esposo Mário Aikanã." (SILVA, 2012, p. 13).

Voort (2013), por sua vez, utiliza estudos anteriores, realizados in loco, bem como alguns textos de sua autoria, já publicados, como fonte dos dados, não discriminando os informantes do que apresenta como "um pequeno esboço preliminar da língua Aikanã" (VOORT, 2013, p. 360). 
Na mesma linha encontram-se os dados de Birchall, em comunicação pessoal, expostos em Storto (2019), que tomou como base, para a apresentação das características fonológicas das línguas indígenas brasileiras, "estudo realizado por Storto e Demolin (2012) de 16 famílias ou línguas do país a partir de artigos publicados em Dixon e Aikhenvald (1999)" (STORTO, 2019, p. 133). Tais dados são apresentados na seção "Exemplos de sistemas fonológicos", da qual nos utilizamos para a produção deste artigo.

Expostos os aspectos metodológicos dos trabalhos utilizados em nossa revisão bibliográfica, antes de adentrarmos especificamente no sistema vocálico da língua Aikanã, fazse necessário um parágrafo para que possamos melhor explicar a nossa metodologia.

Com o fim de constituirmos o quadro fonológico de vogais orais do Aikanã, inicialmente realizamos levantamento bibliográfico de estudos já feitos sobre a língua indígena em estudo, especificamente contemplando os aspectos fonético-fonológicos elencados. Paralelamente a isso, realizamos transcrição fonética da história tradicional do povo Aikanã $O$ Tracajá, cujo áudio foi realizado em dezembro de 2006 pela equipe do Museu Paraense Emílio Goeldi na Aldeia Gleba, Terra Indígena Tubarão Latundê, em que consta uma informante da etnia.

Após ter sido feito o levantamento bibliográfico e a transcrição fonética, baseando-nos nos materiais disponíveis, mais especificamente os dicionários da língua - Silva (2012) e Silva et al. (s/d) - selecionamos palavras para que pudéssemos verificar a presença de pares mínimos e, assim, chegar ao inventário fonológico da língua Aikanã. Mesmo que tais dicionários não possuam transcrição fonética e/ou fonológica de seus verbetes, o conhecimento de que a língua em estudo optou pela grafia o mais próxima possível da oralidade nos serviu como ponto de partida para a seleção de vocábulos. Além da correspondência fonema-grafema, também nos baseamos em conhecimentos próprios sobre a língua e recorremos, para dirimir quaisquer dúvidas que pudessem se apresentar quanto à pronúncia das palavras, à Luciana e à Mariana Aikanã, que pronunciaram as palavras elencadas para que pudéssemos transcrevê-las o mais fielmente possível.

De posse de todos os dados - da revisão bibliográfica e da transcrição da história $O$ Tracajá - pudemos, então, modelar um quadro fonológico de vogais orais da língua Aikanã, para que possa servir de base para novos e mais aprofundados estudos sobre o inventário fonético-fonológico da língua em questão.

Passemos, pois, a seguir, para a exposição de dados sobre o inventário fonéticofonológico vocal da língua Aikanã.

\section{Inventário vocálico do Aikanã}

Como feito anteriormente, apresentaremos cronologicamente os estudos consultados. Iniciamos, portanto, com Vasconcelos (2002), que apresenta um quadro de "onze (11) vogais com estatuto fonológico, das quais seis (06) são orais (/i/, /ع/, /ö/, /a/ /u/ /o/) e quatro (04) são nasais" (VASCONCELOS, 2002, p. 22). Diz ainda que 
[...] há várias possibilidades fonéticas, tanto para as vogais orais, quanto para as nasais. No entanto, como é de se esperar, a maioria delas são variantes de uma única forma básica. Uma observação detalhada do comportamento das vogais, especialmente as não-anteriores, mostra uma tendência que elas têm de se deslocar para a região mediana da cavidade oral, de sorte que há uma "invasão" de espaços normalmente reservados para outros fonemas. Verifica-se, por exemplo, que /a/, e /o/ tendem a subir enquanto que / $\mathrm{u} /$ tende a descer. (VASCONCELOS, 2002, p. 22).

Já quanto ao estatuto fonético, apresenta o seguinte quadro:

Quadro 1 - Quadro fonético das vogais orais

\begin{tabular}{|c|c|c|c|c|}
\hline \multicolumn{2}{|r|}{ Anterior } & \multicolumn{2}{|c|}{ Central } & \multirow{2}{*}{$\begin{array}{c}\text { Posterior } \\
\text { Arredondada }\end{array}$} \\
\hline & $\begin{array}{c}\text { Não } \\
\text { arredondada }\end{array}$ & Arredondada & $\begin{array}{c}\text { Não } \\
\text { arredondada }\end{array}$ & \\
\hline \multicolumn{5}{|l|}{ ALTA } \\
\hline Alta alta & $\mathrm{i}$ i: & ü ü: & $\ddot{1}$ & $\mathrm{u} \mathrm{u}$ : \\
\hline Menos alta & I I: & $\ddot{U} \ddot{U}:$ & & U U: \\
\hline \multicolumn{5}{|l|}{ MÉDIA } \\
\hline Média média & e e: & ö ö: & $\partial$ & \\
\hline Média baixa & $\varepsilon \varepsilon:$ & & $\Lambda$ & o o: \\
\hline \multicolumn{5}{|l|}{ BAIXA } \\
\hline Mais baixa & æ æ: & & a a: & ० ว: \\
\hline
\end{tabular}

Fonte: Vasconcelos (2002, p. 23).

Na sequência, Ribeiro e Cândido (2006), ao observarem características fonológicas de diversas línguas indígenas, apresentam o seguinte sistema para o Aikanã: /i/, /u/, /e/, /ø/, /০/, /a/.

Em Silva (2012), vemos que o sistema vocálico do Aikanã é formado pelas seguintes vogais orais:

Figura 2 - Inventário fonêmico de vogais orais do Aikanã

i

u

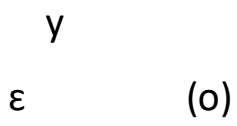

a

Fonte: Silva (2012, p. 14).

A autora relata ainda que, "quase sempre" (SILVA, 2012, p. 14), a vogal /a/ realiza-se como [i], antes de /i/. além disso, alerta:

- o estatuto fonêmico de o é duvidoso. Por um lado, há uma flutuação constante entre [u] e [o]; por outro lado, não encontramos pares mínimos incontestáveis entre $\underline{\mathbf{u}}$ e o. a diferença fonética que encontramos, por exemplo, entre purr $\boldsymbol{\varepsilon}$ macaco e peror $\underline{\varepsilon}$ saliva poderia ser simplesmente contextual. (SILVA, 2012, p. 14, grifos da autora). 
Em Voort (2013, p. 362), verifica-se, no sistema fonológico do Aikanã, a presença das vogais orais /a, e, i, o, u/, esclarecendo, entretanto, que optou por utilizar "uma ortografia fonêmica prática"8. E explica: "Os valores fonéticos dos símbolos não óbvios, conforme o International Phonetic Alphabet, são: /a/ [a], mas antes de [i], o [a] é sempre pronunciado

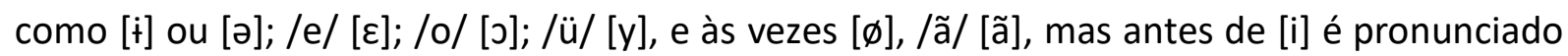
como [f̈] ou [ã]." (VOORT, 2013, p. 362).

Já Birchall (apud STORTO, 2019, p. 145) propõe que o inventário do Aikanã seja composto por /i/, /e/, /a/, /u/, com o acréscimo de uma vogal anterior não arredondada.

Os dados aqui elencados podem ser mais bem visualizados no quadro a seguir, onde se demarca com (\#) aqueles pertencentes apenas ao nível fonético.

Quadro 2 - Estudo comparativo das vogais orais do Aikanã

\begin{tabular}{|c|c|c|c|c|c|}
\hline & $\begin{array}{l}\text { Vasconcelos } \\
\text { (2002) }\end{array}$ & $\begin{array}{l}\text { Ribeiro e Cândido } \\
\text { (2006) }\end{array}$ & $\begin{array}{c}\text { Silva } \\
\text { (2012) }\end{array}$ & Voort (2013) & $\begin{array}{c}\text { Birchall (apud STORTO, } \\
\text { 2019) }\end{array}$ \\
\hline \multicolumn{6}{|c|}{ Anterior } \\
\hline $\mathrm{i}$ & $*$ & $*$ & $*$ & $*$ & \multirow[t]{2}{*}{$*$} \\
\hline y & & & $*$ & $\#$ & \\
\hline I & & & & & \multirow{3}{*}{$*$} \\
\hline e & & $*$ & & $*$ & \\
\hline$\varepsilon$ & $*$ & & $*$ & $\#$ & \\
\hline a & $*$ & * & $*$ & $*$ & $*$ \\
\hline \multicolumn{6}{|c|}{ Central } \\
\hline$\dot{\dagger}$ & & & $\#$ & $\#$ & \multirow[t]{4}{*}{$*$} \\
\hline$\forall$ & & & & & \\
\hline$\partial^{9}$ & $*$ & & & \# & \\
\hline$\varnothing$ & & $*$ & & $\#$ & \\
\hline \multicolumn{6}{|c|}{ Posterior } \\
\hline $\mathrm{u}$ & $*$ & $*$ & $*$ & $*$ & \multirow[t]{3}{*}{$*$} \\
\hline 0 & $\#$ & $*$ & $*$ & $*$ & \\
\hline כ & & & & $\#$ & \\
\hline
\end{tabular}

Fonte: Adaptado de Silva (2019).

Em relação aos dados do Quadro 2, o primeiro ponto que podemos levantar refere-se às metodologias empregadas e aos objetivos dos estudos aqui elencados, descritos anteriormente: o inventário fonético não é contemplado nem em Ribeiro e Cândido (2006) nem em Birchall (apud STORTO, 2019).

\footnotetext{
${ }^{8}$ Lembramos que este artigo objetiva apenas a atualização do inventário fonológico de vogais orais da língua Aikanã. Assim, a escolha de Voort (2013) por uma transcrição fonêmica prática é utilizada sem considerar possíveis interferências que tal metodologia pode trazer à composição final do quadro fonológico da língua Aikanã, que ainda não se encontra concluído.

${ }^{9}$ Conforme Boer (2001, p. 90), /† ə/ podem ser representados, respectivamente, por /ü ö/. Assim: “/ö/ é uma vogal anterior arredondada, fonologicamente média, que tem as seguintes variantes: [ü], [Ü] e [ö]" (VASCONCELOS, 2002, p. 26).
} 
Há consenso quanto à presença de /i, a, u/; diferentemente de todos os outros segmentos vocálicos listados. Vê-se, por exemplo, que /o/ pertence ao sistema fonológico do Aikanã para Ribeiro e Cândido (2006), Silva (2012) e Voort (2013); já para Vasconcelos (2002), o segmento encontrar-se-ia no nível fonético.

Tal situação também se verifica com $[y, \varepsilon, \partial, \varnothing, ~ \supset]$ : para Voort (2013), são segmentos do inventário fonético, divergente do que apontam os outros autores que classificam os segmentos no nível fonológico: Silva (2012), /y/; Vasconcelos (2002) e Silva (2012), /ع/; Vasconcelos (2002), /ə/; Ribeiro e Cândido (2006), / $/$.

O que vemos, então, a partir dos dados expostos no Quadro 2 é um não consenso em relação ao sistema fonético-fonológico da língua Aikanã, fato que pode ser explicado, entre outros, por fatores como o tempo entre os estudos utilizados e as influências sofridas pelo contato com a língua portuguesa ${ }^{10}$, o que carece de investigações mais detalhadas para que se possa caracterizar um quadro de variação diacrônica e/ou de mudança linguística. Como explica Boer:

\begin{abstract}
Stable vowel systems can be maintained in populations that change, even though the number of vowel prototypes might be smaller than in populations that do not change. [...] In the data presented so far in this chapter, it has been shown that the same mechanism that was responsible for the emergence of the vowel systems in the unchanging populations could also be used by new agentes to learn na existing vowel system. If it is shown that the same mechanism can be used for making a vowel system emerge in changing population, this supports Steel's hypothesis (Steels 1997b, Steels 1998a) that the same mechanisms that are responsible for learning language could be responsible for the emergence of a new language. ${ }^{11}$ (BOER, 2001, p. 79, grifos nossos).
\end{abstract}

A inserção de escolas na Terra Indígena Tubarão Latundê, cujo ensino é bilíngue do 40 ao 9o ano, pode ser um dos fatores que fez emergir um novo sistema vocálico, ou que reconfigurasse aquele encontrado. Cita-se, como exemplo, Vasconcelos (2002), cujos dados foram coletados entre 1988 e 1994, antes da inauguração das escolas estaduais indígenas de ensino fundamental e médio Aikanã, localizada na Aldeia Rio do Ouro, em 1992, e Capitão Aritimon, localizada na aldeia Tubarão, em fevereiro de 199412. Tal fato, provavelmente, mudou os mecanismos responsáveis pelo aprendizado da linguagem, fazendo, por conseguinte, emergir uma nova configuração do sistema vocálico do Aikanã, em conformidade com o que expôs anteriormente Boer (2001).

\footnotetext{
10 Devido aos aspectos metodológicos dos trabalhos aqui utilizados, não há como averiguar questões que abranjam aspectos sociolinguísticos como idade, grau de escolaridade, nível de contato com a língua portuguesa, entre outros não adotados ou não listados pelos autores.

11 “Os sistemas de vogais estáveis podem ser mantidos em populações mutáveis, embora o número de protótipos de vogais possa ser menor do que em populações imutáveis. [...] Nos dados apresentados até agora neste capítulo, foi demonstrado que o mesmo mecanismo que foi responsável pela emergência dos sistemas de vogais nas populações imutáveis também poderia ser utilizado por novos agentes para aprender um sistema de vogais existente. Se demonstrar-se que o mesmo mecanismo pode ser usado para fazer emergir um sistema de vogais numa população mutável, isto apoiaria a hipótese de Steel (Steel 1997b, Steels 1998a) de que os mesmos mecanismos que são responsáveis pela aprendizagem da língua poderiam ser responsáveis pela emergência de uma nova língua." (BOER, 2001, p. 79, grifos nossos, nossa tradução).

${ }^{12}$ Dados do Núcleo de Educação Escolar Indígena (NEEI), SEDUC de Vilhena, RO.
} 
Tendo em mente tal fato, acrescentamos aos estudos do Quadro 2 o sistema fonético das vogais orais da língua Aikanã resultante da transcrição do texto O Tracajá (2006). Vejamos:

Quadro 3 - Estudo comparativo das vogais orais do Aikanã - resultado final

\begin{tabular}{|c|c|c|c|c|c|c|}
\hline & $\begin{array}{c}\text { Vasconcelos } \\
\text { (2002) }\end{array}$ & $\begin{array}{c}\text { Ribeiro e } \\
\text { Cândido (2006) }\end{array}$ & $\begin{array}{l}\text { Silva } \\
\text { (2012) }\end{array}$ & $\begin{array}{l}\text { Voort } \\
\text { (2013) }\end{array}$ & $\begin{array}{l}\text { Birchall (apud } \\
\text { STORTO, 2019) }\end{array}$ & $\begin{array}{l}\text { Transcrição de } \\
\text { texto }\end{array}$ \\
\hline \multicolumn{7}{|c|}{ Anterior } \\
\hline $\mathrm{i}$ & * & * & $*$ & $*$ & $*$ & \# \\
\hline $\mathrm{y}$ & & & $*$ & \# & & \# \\
\hline I & & & & & & \# \\
\hline e & & $*$ & & $*$ & $*$ & \# \\
\hline$\varepsilon$ & * & & * & \# & & \# \\
\hline $\mathrm{a}$ & $*$ & $*$ & $*$ & $*$ & * & \# \\
\hline \multicolumn{7}{|c|}{ Central } \\
\hline$\dot{\mathrm{i}}$ & & & $\#$ & \# & $*$ & \# \\
\hline 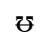 & & & & & & \# \\
\hline$\partial$ & & & & \# & & \# \\
\hline$\varnothing$ & & $*$ & & $\#$ & & \\
\hline \multicolumn{7}{|c|}{ Posterior } \\
\hline $\mathrm{u}$ & * & $*$ & $*$ & $*$ & $*$ & \# \\
\hline o & $\#$ & $*$ & $*$ & $*$ & & \# \\
\hline$\ddot{o}$ & $*$ & & & & & \\
\hline 0 & & & & \# & & \# \\
\hline
\end{tabular}

Fonte: A autora.

Em relação aos dados expostos no Quadro 3, vemos, assim como no Quadro 2, que há consenso apenas quanto aos segmentos /i, a, u/, o que também comprovamos, a seguir, quanto ao nível fonológico do Aikanã.

Quanto aos segmentos listados pelos autores consultados, verifica-se a ausência de $[\varnothing]$ e de [ö] na transcrição fonética do texto $O$ Tracajá. Por outro lado, constata-se a inclusão de [I] e de $[\forall]$, ausentes em todos os inventários utilizados para a composição do quadro comparativo de vogais orais da língua Aikanã.

Assim, tendo em vista a complexidade no resultado das descrições elencadas no Quadro 3, optamos pela busca de pares mínimos, afinal,

In describing a language, one has first to make an inventory of which distinctions of sound make a distinction in meaning, that is, which phonemes the language uses. It is usually possible to derive a fairly unambiguous analysis of the set of phonemes of a language ${ }^{13}$. (BOER, 2001, p. 06).

\footnotetext{
13 “Ao descrever uma língua, é preciso primeiro fazer um inventário de quais distinções de som fazem distinção no significado, ou seja, quais fonemas a língua usa. É normalmente possível obter uma análise bastante inequívoca do conjunto de fonemas de uma língua." (BOER, 2001, p. 06, tradução nossa).
} 
Para tanto, como já expusemos anteriormente, utilizamos os dicionários da língua Aikanã, Silva (2012) e Silva et al. (s/d); as palavras coletadas foram pronunciadas por falantes da língua Aikanã e transcritas. Chegou-se, assim, aos seguintes pares mínimos:

a) apu- [a'pu] produzir um som; zoar (motor); aperceber-se de, dar-se conta de, ver / apa- [a'pa] chamar-se, ter nome de;

b) aru ['aru] jenipapo / ara ['ara] cacau;

c) are [a'rc] ser, estar feio, malfeito / ary [a'ri] abundar (pó, areia, grão);

d) ba'ba [ba'ba] pai / ba'bi [ba'bi] tio;

e) tii ['tìy] tia / tu'i [tu'i] garfo;

f) -rüoa [aru'wa] jacaré / -rüwa [ary'wa] cachorro;

g) kapu- [ka'pi] está bom / kape [ka'pe] café;

h) -nüpe [nae'pe] área limpa em volta da casa /-nüpi [nae'pi] capim;

i) -penaka [pena'ka] calcanhar de /-penika [peni'ka] testículos de;

j) hana- [ha'na] estar juntos, próximos, acostados / hane- [ha'nc] água;

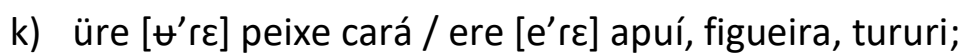

I) jo(a) - [io-] chorar, uivar/ -jũã [iũ'ã] canto, ângulo, esquina / jãu- [i'ã] atirar (pedra etc.), perder, esquecer.

Tais fatos permitiram que se apurasse mais rigorosamente quais os sons da língua Aikanã, dentre os elencados nos quadros 2 e 3, pertenceriam ao seu sistema fonológico, no que diz respeito às vogais orais, os quais sintetizamos a seguir.

Figura 1 - Sistema fonológico de vogais orais da língua Aikanã

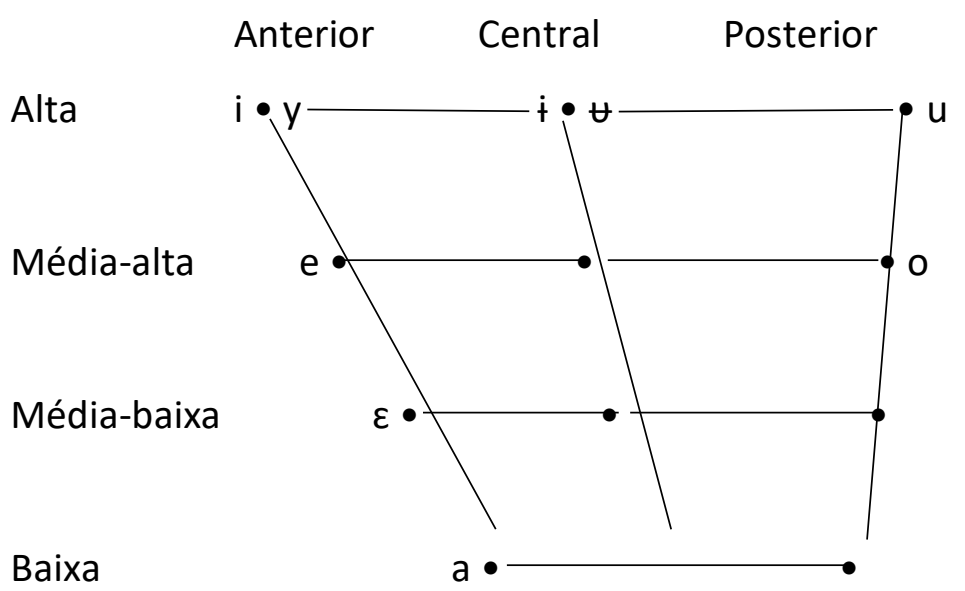

Fonte: A autora.

Tem-se, assim, um sistema de vogais orais composto de 9 fonemas, alguns dos quais considerados, anteriormente, como alofones: "The central vowel [i] [...] are allophones of the phonemes /a/ [... $]^{14 "}$ (BIRCHALL et al., 2017, p. 408). Ainda a respeito de /ł/, lembremo-nos

14 “A vogal central [i] [...] é alofone do fonema /a/ [...]" (BIRCHALL et al., 2017, p. 408, tradução nossa). 
do que disseram Ribeiro e Cândido sobre a sua presença poder ser "uma propriedade tipológica das línguas indígenas brasileiras" (RIBEIRO; CÂNDIDO, 2006, p. 10).

Também em relação ao sistema fonológico de vogais orais da língua Aikanã, a ausência de / / pode demarcar "preferência pelas vogais mais altas /e/ e /o/", como também expõem Ribeiro e Cândido (2006, p. 11). Tal ausência configura o sistema vocálico do Aikanã como assimétrico, tendo em vista a ausência de pares mínimos que confirmem a oposição entre $/ \varepsilon /$ e / /; entretanto, tal quadro é condizente com 34 das 107 línguas indígenas analisadas por Ribeiro e Cândido (2006), além de ser condizente com um dos universais propostos por Crothers (apud BOER, 2001): línguas com cinco ou mais vogais possuem / $\varepsilon /$ em seu sistema e, em geral, mas não necessariamente, possuem $/ \mathrm{J}$.

Quanto aos universais propostos por Crothers (apud BOER, 2001), verifica-se que o sistema fonológico de vogais orais da língua Aikanã atende, além do elencado anteriormente, mais 9 dos 12 indicados: (a) todas as línguas possuem /i/, /a/ e /u/; (b) línguas com quatro ou mais vogais possuem / $\mathfrak{t} /$ ou $/ \varepsilon /$; (c) línguas com sete ou mais vogais possuem, no sistema fonológico, /e o/, ou /ł ə/; (d) línguas com oito ou mais vogais possuem /e/; (e) línguas com nove ou mais vogais geralmente possuem /o/; (f) o número de distinções de altura é igual ou maior do que o número de distinções de posterioridade; (g) a língua com duas ou mais vogais centrais sempre tem uma alta; (h) o número de vogais centrais não pode exceder o número de vogais anteriores ou posteriores; (i) o número de distinções de altura das vogais anteriores é igual ou maior do que o das vogais posteriores.

Em relação ao universal (e), importante se faz retomar Silva (2012, p. 14), que apregoa que "o estatuto fonêmico de o é duvidoso" havendo "uma flutuação constante entre [u] e [o]", sem evidência de pares mínimos pares mínimos inegáveis entre as duas vogais, fato com o qual concordamos parcialmente, tendo em vista, como demonstrado no par mínimo (I), a existência de dois fonemas, /o/ e /u/, mesmo que tal flutuação possa ocorrer em determinados contextos.

\section{Considerações finais}

Este trabalho teve o objetivo de apresentar um quadro fonético-fonológico comparativo quanto às vogais orais da língua Aikanã, com o fim de atualizar e de delinear o seu sistema fonológico vocálico, no que diz respeito às vogais orais.

A partir da montagem de tal quadro comparativo, pudemos verificar a controvérsia de sua constituição; por exemplo, /e/ compõe o sistema fonológico do Aikanã de acordo com dados de Ribeiro e Cândido (2006), Voort (2013) e Birchall (apud STORTO, 2019); já quanto a /ə/, é considerado fonema em Vasconcelos (2002), mas alofone em Voort (2013); somente a presença da vogal /a/ é consenso entre todos - Vasconcelos (2002), Ribeiro e Cândido (2006), Silva (2012), Voort (2013) e Birchall (apud STORTO, 2019).

Desse modo, inserimos transcrição feita a partir do texto $O$ Tracajá, com o fim de realizar nova descrição dos segmentos vocálicos do Aikanã, considerando somente as 
propriedades articulatórias do aparelho fonador, optando, portanto, por não discutir sobre os aspectos suprassegmentais e prosódicos do sistema vocálico.

Chegou-se, assim, a um sistema vocálico composto de 9 vogais orais $-/ i, y, e, \varepsilon, \dot{i}, \forall, a$, $\mathrm{u}, \mathrm{o} /$ - que condiz com 10 dos universais propostos por Crothers (apud BOER, 2001), além de se encaixar no quadro das línguas indígenas brasileiras proposto Ribeiro e Cândido (2006, p. 11).

Ainda em conformidade com as transcrições feitas do texto $O$ Tracajá, em relação à vogal /ə/, pudemos inferir que tal segmento pertence ao nível fonético, e parece estar ligada a variações dialetais e/ou etárias, o que foge do nosso objetivo neste estudo. No entanto, podemos colocar a vogal [i] como sua variante, condizente com o que se apregoa nos estudos das línguas indígenas brasileiras, que ponderam ser a ocorrência de [i] maior do que de [ə] na região Amazônica, onde se encontram os falantes do Aikanã. Nesta língua, parece que o contrário acontece: como indicam os pares mínimos aqui trabalhados, no inventário fonológico teríamos / $/$ /, sendo [ə], possivelmente, uma forma variante.

Já em relação às vogais nasais, nossos estudos ainda estão em andamento, tendo em vista a complexidade do quadro vocálico da língua e a morosidade do trabalho do pesquisador para se obter bons resultados. Pelo mesmo motivo, os fonemas não encontrados nesta distribuição complementar inicial serão investigados posteriormente quanto à alofonia, com o intento de delinearmos tanto um quadro fonético quanto um quadro fonológico mais completo das vogais da língua Aikanã.

Ressaltamos que não intentamos fornecer uma análise exaustiva dos processos fonético-fonológicos da língua Aikanã, nem que este estudo seja conclusivo. Lembramos que este trabalho não compreende uma análise exaustiva da língua, intentando apenas apresentar alguns aspectos da fonologia Aikanã. Há, portanto, espaço para o tratamento mais aprofundado das questões de natureza fonético-fonológicas.

\section{Referências}

BIRCHALL, Joshua et al. Aikanã. In: STENZEL, Kristine; FRANCHETTO, Bruna (Eds.). On this and other worlds: voices from Amazonia. Berlin: Language Science Press, 2017. p. 405-438.

BOER, Bart de. The origins of the vowel systems. New York: Oxford University Press Inc., 2001. CAMARA Jr, Joaquim Mattoso. Problemas de Linguística descritiva. 19. ed. Petrópolis: Vozes, 2002.

CREVELS, Mily; VOORT, Hein van der. The Guaporé-Mamoré region as a linguistic area. In: MUYSKEN, Pieter (Ed.). From linguistic areas to areal linguistics. Amsterdam/Philadelphia: John Benjamins, 2008. p. 151-179. https://doi.org/10.1075/slcs.90.04cre

CROTHERS, John. Typology and universals of vowel systems. In: GREENBERG, Joseph H.; FERGUSON, Charles A.; MORAVCSIK, Edith A. (Eds.). Universals of human language, Stanford, v. 2, 1978. p. 93-152.

EVERETT, Daniel L. Periphrastic pronouns. International Journal of American Linguistics, Manchester, v. 71, n. 3, p. 303-326, 2005. 
FIRCHOW, Irwin; FIRCHOW, Jacquelini. An abbreviated phoneme inventory. Anthropological Linguistics, Bloomington, v. 11, n. 9, p. 271-276, 1969.

GORDON, Gordon; RAYMOND G., Jr. (Ed.). Ethnologue: languages of the world. 15. ed. Dallas: SIL International, 2005. Disponível em: <http://www.ethnologue.com/>. Acesso em: 09 dez. 2019.

MADDIESON, Ian. Patterns of sounds. Cambridge: Cambridge University Press, 1984.

O TRACAJÁ. Gravação: Hein van der Voort. Belém, PA: Museu Paraense Emilio Goeldi, 2006. 1 DVD (16min52s), son., color., legendado.

RIBEIRO, Lincoln Almir Amarante; CÂNDIDO, Gláucia Vieira. O comportamento fonológico das vogais orais nas línguas indígenas brasileiras. Revista Virtual de Estudos da Linguagem REVEL, v. 4, n. 7, n. p., 2006.

RONDÔNIA. Censo populacional da Terra Indígena Tubarão Latundê. Vilhena: FUNAI, 2017.

SNYMAN, Jan W. An introduction to the !X. Cape Town: Balkema, 1970.

SILVA, Janaína Carvalho de Lima; TONDINELI, Patrícia Goulart. O comportamento das vogais na língua indígena Aikanã. Instrumento Crítico - Revista de Estudos da Linguagem, Vilhena, v. 5, n. 5, p. 137-149, 2019.

SILVA, Maria de Fátima dos Santos da. Dicionário de raízes da língua Aikanã. 2012. 167 f. Dissertação (Mestrado em Ciências da Linguagem) - Departamento de Letras e Pedagogia, Fundação Universidade Federal de Rondônia, Guajará-Mirim, 2012.

SILVA, Elissandra Barros da. Estruturas fonéticas e fonológicas de vogais e consoantes da língua Kuruaya. 2008. 139 f. Dissertação (Mestrado em Letras) - Centro de Letras e Artes, Universidade Federal do Pará, Belém, 2008.

SILVA, Maria de Fátima dos Santos da et al. Primeiro dicionário da língua Aikanã. Porto Velho: Secretaria Estadual de Educação de Rondônia, [20-?].

STORTO, Luciana. Línguas indígenas: tradição, universais e diversidade. Campinas: Mercado de Letras, 2019.

ORGANIZAÇÃO DAS NAÇÕES UNIDAS PARA A EDUCAÇÃO, A CIÊNCIA E A CULTURA - UNESCO. Atlas interativo de línguas em perigo. Paris, França, 2010. Disponível em: <http://www.unesco.org/languages-atlas/>. Acesso em: 10 dez. 2019.

VASCONCELOS, Ione Pereira. Aspectos da fonologia e morfologia da língua aikanã. 2002. 78 f. Tese (Doutorado em Linguística) - Programa de Pós-graduação em Letras e Linguística, Universidade Federal de Alagoas, Maceió, 2002.

VOORT, Hein van der. Fala fictícia fossilizada: o tempo futuro em Aikanã. Bol. Mus. Para. Emílio Goeldi. Cienc. Hum., Belém, v. 8, n. 2, p. 359-377, 2013. https://doi.org/10.1590/S1981$\underline{81222013000200009}$

WETZELS, Leo. Estudos fonológicos das línguas indígenas brasileiras. Rio de Janeiro: Editora UFRJ, 1995. 